Backlogs through Bottlenecks in Warehouse Pickups Areas: A Case Study Gulf Nails Manufacturing LLC Ahmed Said Mohammed Said Al Saqri', Panagiotis Nikolaou ${ }^{2}$

Middle East College, Oman

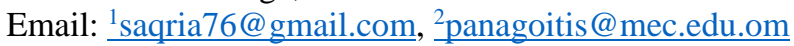

Citation: Al Saqri, A.S.M.S. \& Nikolaou, P. (2021). Addressing Backlog in Warehouse Pickups Areas: A Case Study - Gulf Nails Manufacturing LLC. International Journal of Research in Entrepreneurship \& Business Studies, 2(3), 27-36.

https://doi.org/10.47259/ijrebs.233

Received on $24^{\text {th }}$ Apr. 2021

Revised on $20^{\text {th }}$ May. 2021

Published on $19^{\text {th }}$ Jun. 2021

Copyright: (c) 2021 by the authors. Licensee Global Scientific Publications, Oman.

\section{Publishers Note:}

This work is licensed under a Creative Commons Attribution-ShareAlike 4.0 International License. This is an openaccess journal and the articles published in this journal are distributed under the terms of CC-BY-SA.

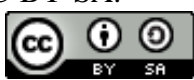

\begin{abstract}
Purpose: The study aims to investigate backlogs within the picking procedures, to find out what is causing storage picking bottlenecks, and to estimate its effect on creating throughout warehouse picking operations.
\end{abstract}

Design/methodology/approach: For this study, a survey questionnaire was used to collect data from a primary source. The staff of the Gulf Nails Enterprise was taken into account as the population of the study. A total of 20 responses were recorded from the population of 50 persons employed in the company. The collected data was analyzed quantitatively to bring out the results.

Findings: The findings confirmed that the most of the warehouse pickup area bottlenecks occur due to least adaptation towards technologies. It is shown that the bottleneck issue could affect 20 to 30 percent of the production line. It is also evidenced that not only tools but strategic planning and efforts by the staff are extremely important in solving a bottleneck issue.

Research limitations/implications: The study recommended that an inventory management system would keep the bottlenecks in check. Introducing modern technology, could help to solve such issues so that human efforts would not be wasted. It is also suggested that the firm should not rely fully on the technology solutions as it is also one of the causes of bottlenecks.

Social implications: This paper will help understand, recognize and solve the various issues faced by the majority of companies in the area of warehouse pickups, not only in Oman but outside as well.

Originality/Value: There has been a lot of studies and research on several areas of warehouse operations but none so far on the topic of the general pickup area of the warehouse.

Keywords: Bottleneck, Backlogs, Pickup areas in Warehouse, Manufacturing companies in Oman, Warehouse Management System tools.

\section{Introduction}

Warehousing is an essential component of the supply chain management of a firm. Within logistics, cost control and cost reduction is the main concern (Jermsittiparsert et al., 2019). Warehouse cost involves costs related to space, space management, storage, and labor. The labor involved in managing materials in and out of the warehouse is included in the time management component. Warehouse-based businesses bear certain costs for which different calculations are done mannerly ( $\underline{\text { Speh}}$, 2009).

Kasimov (2016) explained the 'Bullwhip effect' as one of the most common warehouse management issues that occur within the majority of the firms. It is considered as one of the precise mutual occurrences and the integral consequence via the inventory/order-to-delivery phase. Once it occurs, it can face undesirable consequences of organizational success towards supply chain management. Such a phenomenon arises due to the supply chain propagation through request demand irregularities arises. 
Congestion within the supply chain might appear towards components within the machine. Such a scene happens while its previous phase completes the task sooner than the time. The next step and the procedure partake in achieving the firm's goals due to the low efficiency of inefficient labor or machines. Since a firm's terminal produces a certain logjam, the production line has the greatest standard to remain manipulated that implies the highest probability for a firm's production crashing leading to a bottleneck.

A bottleneck in a supply chain can also be referred to as a situation, in which a commodity takes the most duration for a specific request. Items that are hailed or need to be completed early, will easily overflow storage rooms, forcing workers to wait until continuing the operations work. Such shortfalls become especially harmful towards businesses that produce agricultural or farm commodities having limited useful cycles. For the firm's warehouse capacity to remain effective and efficient, the organization needs to address the issues of warehouses through the implementation of specific right strategies. Ineffective communications exist as some of the factors that lead to warehousing bottlenecks. Most of the frequent challenges of the warehouse operations arise due to the bottlenecks, overstocking with dysfunction within warehouse management, plummet of the motivation of workers, lack work alternative possibilities (Mizgier et al., 2013). These bottlenecks mainly occur within warehouses of manufacturing firms (Kokemuller, 2021).

Equipment usage and job processes are the most common manufacturing bottlenecks. Due to the rise in the bottlenecks, task performance within the pickup areas delay warehouse procedures and the routine tasks get disturbed (Kamali, 2019). According to Wallace (2000), some of the bottlenecks are understaffed or poorly trained personnel, excessive separation among staff duties, obsolete equipment/technologies and facilities. Identifying and eliminating the cause of the appearance bottleneck will boost efficiency that will eliminate wastage of labor and utility.

Manufacturing bottlenecks sourced a heavy downturn in the production capacity of markets which results in deficit and backlogs (Jacobs, 2020). Gravity Flow (2017) identified two types of backlogs within the warehouse's management process:

1. Bottlenecks in the short term - Such backlogs cause the result in momentary/temporary issues. When the key person becomes sick or goes on holiday, no one else is capable of handling his tasks resulting in a job backlog.

2. Bottlenecks that last for a long time - such occurrences are common. Suppose the end-of-the-month control framework gets disrupted every time as a single individual has to perform several sequences with laborious/time-consumption activities.

According to Pegels and Watrous (2005), the root cause of backlogs within warehouse of the manufacturing firms are due to the following bottlenecks:

- Machinery incapability/inefficiency.

- Out-of-date infrastructure, unplanned downtime, and unreliable forecasting.

- Yield losses, reliability issues, and intrinsic capability.

- Variations in overall equipment effectiveness.

- Improper product mix.

The estimation of backlogs will show the indirect impacts of bottlenecks through backlog estimation. Backlog can be estimated in simple four steps viz. Calculating the efficiency within each processing resource (m/activity period or measurements each/per hour); calculating the service demand for each resource; adding the multiple unit request for each commodity - measuring the total demand for a source and measuring the implied utilization (total demand $\div$ capacity of the resources) (Reinboth, 2014).

For example, a production unit with its operating level capacity of $100 \%$ produces 20 merchandise per unit (say). Workers with the firms operate with $100 \%$ capacity whom can produce 10 merchandises in 27 minutes. It can be determined that the production unit is a bottleneck source resulting in producing the least quantity of goods throughout the shortest period.

\section{Research Questions}

This research study attempted to answer the following research questions:

- What triggers bottlenecks throughout the warehouse picking areas?

- What are the causes of bottlenecks within warehouse picking areas? 
- How backlogs can be efficiently addressed?

\section{Research Objectives}

Based on the above research questions the following objectives were defined:

- To investigate backlogs within the picking procedures

- To find out what is causing storage picking bottlenecks

- To estimate its effect of creating throughout warehouse picking operations.

\section{Statement of the Problem}

Warehousing involves regular inbound-bund operations that arrange products for storage and outbound functions that assemble, package, and deliver the product are perceived as simply a place to store finished goods. A single order picker or group of order pickers assigned to the picking zone to pick the batched products from the same area at a specific time. Usually, one order picker can be allotted to each order picker (De Koster et al., 2012). This creates the issue of a bottleneck. The backlog effect within the warehouse pickup operations causes manufacturing firms particularly in Oman with various challenges. It is the major root problem towards managing warehouse especially addressing the backlog clearance in the pickup operation areas is a must and there is a need for the study.

\section{Review of Literature}

Warehouse functions include incoming core strategies and outgoing packaging and distribution functions (Westford University College, 2016). Among storage, processing, between transportation and customers, there should always be warehouse service amenities, built to balance irregular phases with manufacturing, consumption, and service with different modes for transportation (Kabus, 2016).

\section{Importance of Warehousing in Supply Chain and Logistics}

According to Santos international (2015), warehousing provides firms products that involve receiving, storing, and distributing items which appears simpler when all products are being executed in one place and the firms' operating/transportation expenses can be reduced with the help of a warehouse. Ramaa et al. (2012) stated that warehouse logistics include room management, delivery preparation, providing information to ensure that the warehouse runs smoothly. According to Arora (2020), warehousing is an important factor of the supply chain which might not be involved directly with a customer but every sale could not be properly handled without it. According to Kłodawski et al. (2017), the managing warehouse operation is a complicated one but the right tools and strategies to manage warehouse operations can save not only the organization but also provides benefits of saving operation time.

\section{Warehouse Pickup Area Process and its Issues}

According to Burinskiene (2010), order processing is a time-consuming task of the warehouse, retrieving items from designated collection points based on customer demands and the order picking costs is the major part of the total operating cost. Sinisalo (2016) stated that whenever a product is not available in a specific warehouse, every picker will spend too much time and energy looking for the product, causing delay resulting in disgruntled consumers and challenging situation. According to NewcastleSystems (2016), the accuracy with which warehouse workers could perform requests nor coordinate inventory might lead to fraught with problems and a bottleneck might occur because of such inefficient processes, slowing everything down.

\section{Challenges of Bottleneck within Warehouse Pickup Area}

Supply chain management increases customer support, lowers operational budgets, even enhances a company's financial status (Kleab, 2017). Sakthivel and Muralidharan (2019) stated that supply chain management becoming essential standard business practice, which is critical with every business performance as customer retention becomes more important than ever before. A single blunder throughout the distribution chain can create a barrier that slows down the units that come before it (Mizgier et al., 2013). A rise in inventory before a bottleneck and a shortage of parts following such congestion appear common (Hajmirfattahtabrizi and Song, 2019). In critical situations, integration of supply, output, and distribution in manufacturing processes - a procedure of supply chain throughput are determined by the effect of the bottlenecks, addressing it would improve working capital (Sardar and Lee, 2015).

\section{The Benefits of Effective Supply Chain Management to Minimize Occurrence of Bottleneck}

Supply chain management aims to achieve a competitive advantage by conducting operations involving innovative products of consumers' demand with higher costs (Wahyuni, 2010). It helps companies towards cost-saving, reduced order processing periods, and increased product availability enabling merchandise to reach customers quickly (Fawcett et al., 2008). 
Gaps for Growing Firms Manufacturing Warehouse Production

The frequent cause for backlog within warehouse management is the formation of bottlenecks within the warehouse pickup operation and firms must handle them for smooth business overall operations (Hajmirfattahtabrizi and Song, 2019).

\section{Identification of Warehouse Pickup Area Bottleneck and Order Pickup Classification}

Velumani and Tang (2017) stated that the bottleneck might occur at any point in the manufacturing process. Ericson (2017) claimed that a bottleneck exists either due to the slow manufacturing system or the machine not being vacant for long due to disruptions. The lack of importance to the warehouse within the supply chain network leads to unsuccessful warehouse operations and in particular bottleneck in the pickup line area (Moran, 2017). Order picking entails the preparation and delivery of required goods and accomplishment of such tasks $(\underline{\mathrm{Yu}}, 2008)$. Bowles $(2020)$ claimed that order picking accounts for $55 \%$ of operating expenses of the warehouses and the best fit order picking needs to be considered to reduce the expenses. Congestion within the supply causes bottlenecks due to inefficient labor or machines (Hajmirfattahtabrizi and Song, 2019). Gravity Flow (2017) argued that backlogs may occur for numerous circumstances, including outdated technology, insufficient workers, and limited resources. Kikolski (2016) claimed that ensuring high utilization of a workstation processing capability poses several significant challenges towards efficiency with manufacturing procedures.

\section{Impact of Warehouse Bottleneck towards other Department}

Bottleneck within the manufacturing warehouse impacts numerous divisions such as production planning, assembly planning, and human resource planning (Higgins, 2013). Sticking the position code at the end of the operation slows down the firm's entire procedure as the operation package can be processed throughout only after the label is applied (Stouwdam, 2010). Processing time is a non-value-adding operation that can be classified as waste in a procedure (Hanus, 2015). The manufacturing process takes a longer duration due to inefficient system and huge capacity of manufacture consignments, forming backlog (Feldt et al., 2019).

\section{Technologies to Solve Warehouse Bottleneck Target}

Custodio and Machado (2020) argued that manual order picking involves the efficacy of stock management, methods of selecting or modifying products according to request, and the impact of automated systems. Potential innovative tools such as Warehouse Management System (WMS) entail the framework towards helping warehouses and distribution centers, with the manual order picking through merging interactive digital functionality (Plakas et al., 2020). Visibility, traceability, and related details can be provided by monitoring systems at different phases towards supply chain and logistics, allowing a competitive edge (Nilsson and Merkle, 2018). Rensburg (2019) suggested that technology tools like Enterprise Resource Planning (ERP) solutions could aid the warehouse to resolve the bottleneck issues easily as ERP involves inventory management, and job scheduling services are provided by WMS software, enabling automated systems storing, automatic picking, including hydraulic ram equipment, etc.

\section{Addressing the Bottleneck}

The manufacturing process should be simplified and managed smoothly once a bottleneck is identified and resolved at the earlier stage rather than allowing it to become severe and the employees should be trained and able to identify such bottlenecks at the early stage as a preventative measure (LeanProduction, 2011). Department managers should advise the forefront workers on recognizing the symptoms of a bottleneck and train them in troubleshooting (Wolniak et al., 2018). More power, changing streamline, removing wasted measures, increasing workers, and reducing output are some of the solutions to bottlenecks (LizarraldeAiastui et al., 2020).

\section{Research Methodology}

In this research, a survey questionnaire was used to collect data from a primary resource. Quantitative research is one of the tools for research-based with the simplest to do so and analyze (Canals, 2017). The goal of the research was to resolve its territory's multiple bottlenecks, which was why a quantitative research method was chosen as the best option. The staff of the Gulf Nails Enterprise was taken into account as the population of the study. A total of 20 responses were recorded from the population of 50 persons employed in the company. The 'Gulf Nails' corporation remains the Sultanate of Oman's newest building materials manufacturers, with a well-developed warehousing business. 
The company's warehousing personnel provided the sampling frame list. Senior, middle, and procurement department staff members were involved in this study. Respondents in the first two categories, senior and medium level, were chosen using a selective representative sample in the study. As the warehouse is the host department of the warehouse function, all warehouse and operations staff members were included in the sample. The data collected was analyzed quantitatively to bring out the results.

\section{Findings}

Table 1 Bottlenecks

\begin{tabular}{|l|c|c|c|c|c|}
\hline \multicolumn{1}{|c|}{ Statements } & SD & D & N & A & SA \\
\hline Bottlenecks are one of the most & 3 & 4 & 0 & 11 & 2 \\
frequent terms used within the & $15 \%$ & $20 \%$ & $00 \%$ & $55 \%$ & $10 \%$ \\
Organization's warehouse platform & & & & & \\
\hline
\end{tabular}

Table 1, indicated that $55 \%$ of the respondents agreed that bottlenecks are one of the most frequent terms used within the Organization's warehouse platform. The respondents working in a manufacturing firm and managing the warehouse had heard frequently the term 'bottleneck' within the organization. Only $20 \%$ of the respondents disagreed that they have not heard about it. There is no doubt that the term 'bottleneck' was known within the Gulf Nails warehouse.

Table 2 Bottleneck Frequently Occurring Area

\begin{tabular}{|l|c|c|}
\hline \multicolumn{1}{|c|}{ Occurrence Area } & Frequency & \% \\
\hline Pickup Area & 11 & 55 \\
\hline Production Area & 6 & 30 \\
\hline Storage Area & 2 & 10 \\
\hline Inbound and outbound area & 1 & 5 \\
\hline
\end{tabular}

Table 2 indicated that the majority of the respondents $(55 \%)$ agreed that the pickup area of the warehouse operation is the area where the frequent bottleneck occurs followed by $30 \%$ of the respondents reporting Production area and $10 \%$ of the respondents reporting Storage area. This finding is similar to that of Hajmirfattahtabrizi and Song (2019) wherein they have stated that the occurrence of the bottleneck within the warehouse operation appears in the pickup area, where numerous operation slows down frequently.

Table 3 Reason for the occurrence of Bottlenecks

\begin{tabular}{|l|c|c|}
\hline \multicolumn{1}{|c|}{ Reason } & Frequency & \% \\
\hline Lack of Technologies & 10 & 50 \\
\hline Overload Task Capacity & 4 & 20 \\
\hline Low Employees performance & 3 & 15 \\
\hline Others & 3 & 15 \\
\hline
\end{tabular}

Table 3 indicated that the majority of the respondents (50\%) agreed that it was due to the lack of warehouse technologies that cause the creations of the warehouse bottlenecks followed by $20 \%$ of the respondents agreed that due to the overload of the work capacity bottleneck reported occurring. $15 \%$ of the respondents reported that the reason might be due to low employee performance or due to any other reasons. This finding is similar to Hajmirfattahtabrizi and Song (2019) who have reported that technologies trigger bottleneck creations and lack of technologies will not lead to bottleneck challenges but might cause some other issues to the organization.

Table 4 Technical tool to determine Bottlenecks

\begin{tabular}{|l|c|c|}
\hline \multicolumn{1}{|c|}{ Determining Technical tools } & Frequency & $\mathbf{\%}$ \\
\hline Warehouse Management Systems (WMS) & 4 & 20 \\
\hline Inventory Management Systems & 8 & 40 \\
\hline Employees work rate performance & 6 & 30 \\
\hline Others & 2 & 10 \\
\hline
\end{tabular}

Table 4 indicated that the majority of the respondents (40\%) agreed the inventory management systems tools were preferred to detect the bottlenecks within warehouse operations followed by $30 \%$ of the respondents preferred Employee's work-rate performance to identify the bottlenecks and $20 \%$ of the respondents reporting Warehouse Management Systems (WMS). 
Table 5 Type of Primary Action to be Taken to Solve the Bottlenecks

\begin{tabular}{|l|c|c|}
\hline \multicolumn{1}{|c|}{ Primary Action Taken } & Frequency & \% \\
\hline Identification of bottleneck & 3 & 15 \\
\hline Consequence & 7 & 35 \\
\hline Management to decide & 10 & 50 \\
\hline Preventing from future bottlenecks & 0 & 0 \\
\hline
\end{tabular}

Table 5 indicated that the majority of the respondents (35\%) agreed that the consequent action will be taken when a bottleneck situation arises. $35 \%$ of the respondents agreed that identifying the 'consequence' was used as a primary step to solve bottleneck issues. Only $15 \%$ of the respondents agreed that identification was considered the primary step. No response was recorded towards preventing future bottleneck occurrence.

Table 6 Action taken through External Source to Solve the Bottlenecks
\begin{tabular}{|l|c|c|}
\hline \multicolumn{1}{|c|}{ Action through External Source } & Frequency & $\%$ \\
\hline Seeking third parties to address the issues & 5 & 25 \\
\hline Exploring external source to solve the issues & 9 & 45 \\
\hline No actions necessitated from the external source & 2 & 10 \\
\hline None of the above & 4 & 20 \\
\hline
\end{tabular}

Table 6 indicated that the majority of the respondents (45\%) agreed that exploring external sources to solve the issues was preferred in solving the bottlenecks. $25 \%$ of the respondents agreed that Seeking third parties to address the bottleneck issues was preferred. Only $10 \%$ of the respondents confirmed that no action was necessitated from the external source.

Table 7 Tools Recommended to Solve the Bottlenecks

\begin{tabular}{|l|c|c|}
\hline \multicolumn{1}{|c|}{ Tools Recommended } & Frequency & $\mathbf{\%}$ \\
\hline Different Technical Tools & 1 & 5 \\
\hline Human Efforts only & 3 & 15 \\
\hline Strategic Planning & 5 & 25 \\
\hline All of the above & 11 & 55 \\
\hline
\end{tabular}

Table 7 indicated that $25 \%$ of the respondents recommended Strategic Planning as the tool to solve the bottleneck issues. $15 \%$ of the respondents suggested Human efforts alone to solve the bottlenecks whereas only $5 \%$ recommended adopting different technical tools. The majority of the respondents (45\%) agreed that the combination of all the tools to solve the bottlenecks.

Table 8 Impact of Bottleneck within the Production Line

\begin{tabular}{|c|c|c|}
\hline Agreed Percentage & Frequency & $\boldsymbol{\%}$ \\
\hline $10 \%-20 \%$ & 4 & 20 \\
\hline $20 \%-30 \%$ & 8 & 40 \\
\hline $30 \%-40 \%$ & 4 & 20 \\
\hline $40 \%-50 \%$ & 4 & 20 \\
\hline
\end{tabular}

Table 8 indicated that the majority of the respondents (40\%) agreed that the impact of bottleneck within the production line was $20 \%-30 \% .20 \%$ of the respondents agreed that the impact of the bottleneck within the production line was reported to be all other percentages viz. $10 \%-20 \%, 30 \%-40 \%$ and $40 \%-50 \%$.

Table 9 Areas where Effect could be Reduced

\begin{tabular}{|l|c|c|}
\hline \multicolumn{1}{|c|}{ Areas } & Frequency & \% \\
\hline Warehouse production line & 2 & 10 \\
\hline Pickup area of the warehouse & 6 & 30 \\
\hline Warehouse labor procedure area & 8 & 40 \\
\hline Warehouse technology malfunctions & 4 & 20 \\
\hline
\end{tabular}


Table 9 indicated that the majority of the respondents (40\%) agreed that the areas where the effect could be reduced were warehouse labor procedure areas. $30 \%$ of the respondents agreed that the effect could be reduced was the Pickup area of the warehouse. $20 \%$ of the respondents agreed that the area where the effect could be reduced was Warehouse technology malfunctions.

Table 10 Tools Required to Avoid Bottleneck

\begin{tabular}{|l|c|c|}
\hline \multicolumn{1}{|c|}{ Tools Required } & Frequency & \% \\
\hline Technology tools & 1 & 5 \\
\hline Upgrading Diverse skills sets & 8 & 40 \\
\hline Inventory cycle testing & 4 & 20 \\
\hline Others & 7 & 35 \\
\hline
\end{tabular}

Table 10 indicated that the majority of the respondents (40\%) agreed that upgrading diverse skill sets required to avoid bottlenecks. $20 \%$ of the respondents agreed that Inventory cycle testing is the tool required to avoid bottlenecks. Only $5 \%$ of the respondents agreed that Technology tools were required to avoid bottlenecks. $35 \%$ of the respondents confirmed all other tools.

Table 11 Manner Bottleneck Destruction Caused to Warehouse Area

\begin{tabular}{|l|c|c|}
\hline \multicolumn{1}{|c|}{ Destruction Type } & Frequency & \% \\
\hline Damages & 2 & 10 \\
\hline Inventory management difficulties & 4 & 20 \\
\hline Loss of productions & 8 & 40 \\
\hline Product shortage & 6 & 30 \\
\hline
\end{tabular}

Table 11 indicated that the majority of the respondents (40\%) agreed that bottlenecks lead to loss of productions within warehouse operations. $30 \%$ of the respondents agreed that bottlenecks lead to Product Shortages while $20 \%$ of the respondents agreed that bottlenecks lead to inventory management difficulties. Only $10 \%$ of the respondents agreed that bottlenecks lead to damages within warehouse operations.

\section{Conclusion}

From the above findings, it is concluded that the bottleneck in the warehouse pickup area was found to be problematic for warehouse operation management. This is similar to the study by ALKhatib (2009). It is also concluded that the occurrence of warehouse bottleneck was not a new issue to the Gulf Nails firm. The employees were well aware of the challenges brought in by the bottlenecks within the warehouse pickup operations and the solutions to handle them. Further, the respondents stated that they faced bottlenecks mostly in the pickup area and agreed to the fact that it was mostly due to a lack of proper technology. Most of them also felt that an inventory management system would keep the bottlenecks in check. The majority of them agreed that not only tools but strategic planning and efforts by the staff are extremely important in solving a bottleneck issue. Most of the staff members stated that the bottleneck issue could affect 20 to 30 percent of the production line. Introducing modern technology, it is confirmed that the different types of bottleneck issues could be solved and human labor efforts would not be wasted. Moreover, it was identified that the firm should not rely fully on the technology solutions as it was also one of the causes of bottlenecks. It was identified that most of the warehouse pickup area bottlenecks occur due to least adaptation towards technologies. This finding is similar to the result of the study by Ericson (2017).

\section{Recommendations}

Balancing between human and technology will be the apt solution to handle the bottleneck issues of the firm warehouse pickup operations and the best solution for the Gulf Nails firm towards the identification of the bottleneck issues is clear that the issues could be arrested with the cooperation and the full support of the management. This will result in the development of a coordinated and well-developed overall organizational work procedure. Further, to resolve bottleneck issues, it is advised to increase the number of persons involved in the bottleneck issues team as suggested by Anderson et al. (2021) in a similar study. As suggested by BaAwain and Daud (2018), the company may delegate some employees from another operation to help execute the bottleneck operation during an unutilized period and the company can increase the number of resources running the operation without adding headcount.

The firm should take steps to close the gaps of the bottleneck occurrence in the recent/future warehouse operations through adaptation to technologies. It is suggested that the warehouse should be appropriately 
computerized via technology solutions to enhance the bottleneck of storeroom operations. It is also suggested to keep updating the warehouse technologies to avoid bottleneck occurrences and disturbances. Enhancing information exchange within warehouses, introducing track - and - trace devices with reminders will help to resolve bottleneck issues as suggested by Four Principles (2017).

Without the help of modern technologies, it will be difficult for labor to achieve the company goals within the specified time frame (Masudin et al., 2020). So, employees should also be given advanced training in information technology.

It is also suggested that the Gulf Nails set up advanced strategies to prevent occurrences of warehouse bottlenecks in the coming future.

\section{References}

1. ALKhatib, R. H. (2009). Analyzing the Bottlenecks in Operations Management Using Cause and Effect Diagram. MBA Thesis submitted to Middle East University for Graduate Studies. https://meu.edu.jo/libraryTheses/58734eeee786e_1.pdf

2. Anderson, M. A., MSE, Anderson, E. J. \& Parker, G. (2021). How to Manage Bottlenecks in Operations Management? Dummies, https://www.dummies.com/business/operations-management/how-to-managebottlenecks-in-operations-management/

3. Arora, S. (2020, 31 $1^{\text {st }}$ Aug. 2020). 6 Reasons Why Warehousing is Critical for Supply Chain Management. Shiprocket, https://www.shiprocket.in/blog/warehousing-in-supply-chain-management/

4. Ba-Awain, A. M. S. \& Daud, D. (2018). Oman as A Future Logistics Hub: A Conceptual Study. International Journal of Economics, Commerce and Management, VI(6), 141-148. https://www.researchgate.net/publication/325817424_International_Journal_of_Economics_Commerce an d_Management_OMAN_AS_A_FUTURE_LOGISTICS_HUB_A_CONCEPTUAL_STUDY

5. Bowles, R. (2020). Material Handling 101: How to Keep Your Warehouse Productive. www.logiwa.com, https://www.logiwa.com/blog/warehouse-material-handling

6. Burinskiene, A. (2010). Order Picking Process at Warehouses. International Journal of Logistics Systems and Management, 6(2), 162. https://doi.org/10.1504/ijlsm.2010.030958

7. Canals, L. (2017). Instruments for Gathering Data. In E. Moore \& M. Dooly (Eds.), Qualitative Approaches to Research on Plurilingual Education (pp. 390-401). Research-publishing.net, https://files.eric.ed.gov/fulltext/ED573582.pdf

8. Custodio, L. \& Machado, R. (2019). Flexible Automated Warehouse: A Literature Review and an Innovative Framework. The International Journal of Advanced Manufacturing Technology, 106(1-2), 533558. https://doi.org/10.1007/s00170-019-04588-Z

9. De Koster, R. B., Le-Duc, T. \& Zaerpour, N. (2012). Determining The Number of Zones in a Pick-And-Sort Order Picking System. International Journal of Production Research, 50(3), 757-771.

10. Ericson, A. (2017). Bottleneck Detection in Manufacturing a Throughput Case Study at SCANIA CV. Master's Thesis in Production Engineering. Chalmers University of Technology. https://publications.lib.chalmers.se/records/fulltext/251657/251657.pdf

11. Fawcett, S. E., Magnan, G. M. \& McCarter, M. W. (2008). Benefits, Barriers, and Bridges to Effective Supply Chain Management. Supply Chain Management: An International Journal, 13(1), 35-48. https://doi.org/10.1108/13598540810850300

12. Feldt, J. Kontny, H. \& Wagenitz, A. (2019). Breaking through the Bottlenecks using Artificial Intelligence. Proceeding of the Hamburg International Conference of the Logistics. HICL-27. https://doi.org/10.15480/882.2463

13. Four Principles (2017). Lean Warehouse Operations. Four Principles Management Consulting FZ-LLC, Fourprinciples.com, content/uploads/2017/07/FP_lean_warehouse_operations.pdf https://fourprinciples.com/wp-

14. Gravity Flow. (2017, 21 st Aug. 2017). The Most Common Workflow Bottlenecks (and How to Fix them). Gravity Flow, https://gravityflow.io/articles/the-most-common-workflow-bottlenecks-and-how-to-fix-them/ 15. Hajmirfattahtabrizi, M. \& Song, H. (2019). Investigation of Bottlenecks in Supply Chain System for Minimizing Total Cost by Integrating Manufacturing Modelling Based On MINLP Approach. Applied Sciences, 9(6), 1185. https://doi.org/10.3390/app9061185

16. Hanus, M. (2015). Customer Order Cycle of a Production Company, its Bottlenecks, and Potential for Improvements. https://edepot.wur.n1/350746 
17. Higgins, S. (2013). Beware of Bottlenecks in Manufacturing. Travelers, https://www.travelers.com/iwdocuments/business-insurance/manuf-beware-bottlenecks-cp-7984.pdf

18. Jacobs, T. (2020, $5^{\text {th }}$ Mar. 2020). Bottlenecks in Manufacturing: How to Avoid it? ThroughPut https://throughput.world/blog/industry/bottleneck-in-manufacturing/

19. Jermsittiparsert, K., Sutduean, J. \& Sriyakul, T. (2019). Role of warehouse attributes in supply chain warehouse efficiency in Indonesia. International Journal of Innovation, Creativity, and Change, 5(2). https://www.researchgate.net/publication/335490874_Role_of_Warehouse_Attributes_in_Supply_Chain_ Warehouse_Efficiency in_Indonesia

20. Kabus, J. (2016). Logistics of Warehousing. World Scientific News, http://www.worldscientificnews.com/wp-content/uploads/2015/10/WSN-48-2016-63-68.pdf

21. Kamali, A. (2019). Smart Warehouse Vs. Traditional WarehouseReview. Ciit International Journal of Automation and Autonomous System, $11(1), 9-14$.

22. Kasimov, I. (2016). Issues in logistics and supply chain management, bullwhip effect, and warehouse management.

https://www.researchgate.net/publication/305143742_Issues_in_Logistics_and_Supply_Chain_Manageme nt_Bullwhip_Effect_and_Warehouse_Management

23. Kikolski, M. (2016). Identification of Production Bottlenecks with the Use of Plant Simulation Software. Ekonomia I Zarzadzanie, 8(4), 103-112. https://doi.org/10.1515/emj-2016-0038

24. Kleab, K. (2017). Important of Supply Chain Management. International Journal of Scientific and Research Publications, 7(9), 397-400. http://www.ijsrp.org/research-paper-0917/ijsrp-p6949.pdf

25. Kłodawski, M., Jacyna, M., Lewczuk, K., \& Wasiak, M. (2017). The Issues of Selection Warehouse Process Strategies. Procedia Engineering, 187(1), 451-457. https://doi.org/10.1016/j.proeng.2017.04.399

26. Kokemuller, N. (2021). What Causes Bottlenecks in a Manufacturing Environment? Small Business Chron.com, https://smallbusiness.chron.com/causes-bottlenecks-manufacturing-environment-71660.html

27. LeanProduction. (2011). Theory of Constraints. Lean Production, Vorne, https://www.leanproduction.com/theory-of-constraints.html

28. Lizarralde-Aiastui, A., Eulate, U.A.D. \& Mediavilla Guisasola, M. (2020). A Strategic Approach for Bottleneck Identification in Make-To-Order Environments: A Drum-Buffer-Rope Action Research Based Case Study. Journal of Industrial Engineering and Management, 13(1), 18-37. https://doi.org/10.3926/jiem.2868

29. Masudin, I., Sumah, B., Zulfikarijah, F. \& Restuputri, D. P. (2020). Effect of Information Technology on Warehousing and Inventory Management for Competitive Advantage: A Theoretical Framework. ResearchGate, https://doi.org/10.4018/978-1-7998-4984-1.ch027

30. Mizgier, K. J., Jüttner, M. P. \& Wagner, S. M. (2013). Bottleneck identification in supply chain networks. International Journal of Production Research, 51(5), 1477-1490. https://doi.org/10.1080/00207543.2012.695878

31. Moran, J. W. (2017). Process Bottleneck Analysis Construction Steps/example. http://www.phf.org/resourcestools/Documents/Process_Bottleneck_Analysis.pdf

32. Newcastle systems. (2016). Warehouse bottlenecks that need your attention. Newcastlesys.com, https://www.newcastlesys.com/blog/warehouse-bottlenecks-that-need-your-attention

33. Nilsson, A. \& Merkle, D. (2018). Technical Solutions for Automation of Warehouse Operations and their Implementation Challenges. Master's Thesis submitted to Linnaeus University. https://www.divaportal.org/smash/get/diva2:1212918/FULLTEXT01.pdf

34. Pegels, C. C. \& Watrous, C. (2005). Application of The Theory of Constraints to A Bottleneck Operation in A Manufacturing Plant. Journal of Manufacturing Technology Management, 6(3), 302-311.

35. Plakas, G., Aretoulaki, E., Ponis, S. T., Agalianos, K. \& Maroutas, T. N. (2021). A Proposed Technology Solution for Enhancing Order Picking in Warehouses and Distribution Centers Based On a Gamified Augmented Reality Application. International Conferences Interfaces and Human-Computer Interaction and Game Entertainment Technologies-2020, Zagreb, Croatia, 217-221. https://www.researchgate.net/publication/343889452_A PROPOSED TECHNOLOGY SOLUTION_FO R ENHANCING_ORDER PICKING_IN WAREHOUSES AND DISTRIBUTION CENTERS BASE D_ON_A_GAMIFIED_AUGMENTED_REALITY_APPLICATION

36. Ramaa, A., Subramanya, K. N. \& Rangaswamy, T. M. (2012). Impact of warehouse management system in a supply chain. International Journal of Computer Applications, 54(1). https://research.ijcaonline.org/volume54/number1/pxc3882062.pdf

37. Reinboth, C. (2014). Operations Management Basics: Finding The Bottleneck In Processes With Multiple Flow Units, SAP blogs, https://blogs.sap.com/2014/09/10/operations-management-basics-findingthe-bottleneck-in-processes-with-multiple-flow-units/ 
38. Rensburg, L. J. V. (2019). Artificial Intelligence for Warehouse Picking Optimization an NP-Hard Problem. Master Thesis submitted to Teknisk- naturvetenskaplig fakultetUTH-enheten, Uppsala Universitet, https://www.diva-portal.org/smash/get/diva2:1413926/FULLTEXT01.pdf

39. Sakthivel, H. \& Muralidharan, H. (2019). Supply Chain Management: The Importance of Integration of Logistics and Business Processes. https://www.researchgate.net/publication/337311751_Title_Supply_Chain_Management_The_Importance of_Integration_of_Logistics_and_Business_Processes

40. Santos International. (2015). Importance of Warehousing in a Logistics System. Santosintl.com, http://www.santosintl.com/Blog/Post/275/Importance-of-Warehousing-In-A-Logistics-System

41. Sardar, S. \& Lee, Y. H. (2015). Modeling the Impact of Border Crossing Bottlenecks on Supply Chain Disruption Risk. International Journal of Engineering and Technology, 7(2), 692-707.

42. Sinisalo, T. (2016). Improving Efficiency of the Order Picking Process in the Case Company Warehouse. https://www.theseus.fi/bitstream/handle/10024/110707/Sinisalo-Timo-Masters-

Thesis.pdf? sequence $=1 \&$ isAllowed $=\mathrm{y}$

43. Speh, T. W. (2009). Understanding warehouse costs and risks. Journal of Logistics, 24(7). https://warehousingforum.com/news/KB_v24n07 June2009.pdf

44. Stouwdam, G. (2010). Warehouse efficiency at Topa verpakking. Mastera Thesis submitted to the University of Twente. http://essay.utwente.nl/60724/1/MSc_Gerben_Stouwdam.pdf

45. Velumani, S. \& Tang, H. (2017). Operations Status and Bottleneck Analysis and Improvement of a Batch Process Manufacturing Line Using Discrete Event Simulation. Procedia Manufacturing, 10, 100-111. https://doi.org/10.1016/j.promfg.2017.07.033

46. Wahyuni, D. (2010). The Importance of Supply Chain Management in Competitive Business: A Case Study on Woolworths. Researchgate, https://www.researchgate.net/publication/228215291_The_Importance_of_Supply_Chain_Management_in _Competitive Business_A Case Study_on_Woolworths

47. Wallace, M. (2000). Effects of A Bottleneck in Warehousing. Small Business - Chron.com, https://smallbusiness.chron.com/effects-bottleneck-warehousing-32369.html

48. Westford University College. (2016, $8^{\text {th }}$ Jan. 2016). Warehousing in Logistics and Supply Chain Management. Westford University College, https://mywestford.com/blog/significance-of-warehousing-inlogistics-and-supply-chain-management/

49. Wolniak, R., Skotnicka-Zasadzień, B. \& Gębalska-Kwiecień, A. (2018). Identification of bottlenecks and analysis of the state before applying lean management. 12th International Conference Quality Production Improvement - QPI 2018. MATEC Web of Conferences, 183, 01001, 1-6. https://doi.org/10.1051/matecconf/201818301001

50. Yu, M. (2008). Enhancing Warehouse Performance by Efficient Order Picking. Doctoral Thesis submitted to Erasmus Research Institute of Management, RSM Erasmus University, https://repub.eur.nl/pub/13691/EPS2008139LIS9058921673YU.pdf 